\title{
VESTIBOLOGY
}

\section{Recurring paroxysmal positional vertigo: evaluation of the vascular factor}

\author{
La valutazione del fattore vascolare nella vertigine parossistica ricorrente \\ Giampiero Neri', Giulio Romano Filograna Pignatelli', Alessandro Pacella ${ }^{1}$, Rocco Ortore², Laith Khasawneh ${ }^{3}$ \\ ${ }^{1}$ Department of Neurosciences Imaging and Clinical Sciences, University Gabriele D'Annunzio of Chieti-Pescara, Italy \\ ${ }^{2}$ Department of Otolaryngology (ENT), IRCCS Hospital Home for the Relief of Suffering, San Giovanni Rotondo, Italy \\ ${ }^{3}$ Department of General and Special Surgery, Hashemite University of Jordan, Zarqa, Jordan
}

\section{SUMMARY}

To evaluate the effective incidence of vascular factor in the recurrence of benign paroxysmal positional vertigo (BPPV), we studied 50 subjects, 32 affected by idiopathic recurrent BPPV (study group) and 18 healthy subjects (control group). All subjects underwent complete otoneurological balance and haemodynamic evaluation by extracranial colour-coded duplex sonography (ECCS) of vertebral arteries (VA) with indication of arterial flow in $\mathrm{ml} / \mathrm{min}$, and retinal fluorangiography (FAG). The ECCS of 19 patients $(59.3 \%)$ within the study group presented a reduction in vertebral arterial flow, exceeding the limits established by normative values $(<100 \mathrm{ml} / \mathrm{min})$. In all cases, the same side was affected by BPPV, emphasised by vertebral hypoperfusion. The remaining 13 patients $(40.6 \%)$ showed an arterial vertebral flow entirely within the normative values. The FAG excluded qualitative alterations of the cerebral microcirculation. The ECCS demonstrated that $59.3 \%$ of the study group showed a significant reduction in vertebral arterial flow ipsilateral to the semicircular canal affected by BPPV. This increased to $68.75 \%$ when the flow difference (D) between both the vertebral arteries were considered and reached $71.8 \%$ when vascular risk factors were evaluated. We conclude that reduced perfusion of the vestibular structures makes an already critical situation even more difficult, which can eventually develop into labyrinth suffering. The absence of fluorangiographic signs suggests that the labyrinthine neuroepithelium is much more sensitive to hypoperfusion than the retina. We hypothesise that this ischaemic situation could degenerate utricular macula, otolith detachment, leading to the development of recurrent BPPV. This risk situation for the labyrinth can also be revealed by the evaluation of three parameters: presence of vascular risk factors, reduction of vertebral flow $<100 \mathrm{ml} / \mathrm{min}$ and the difference in flow between the 2 vertebral arteries $>29 \mathrm{ml} / \mathrm{min}$.

KEY WORDS: BPPV, cerebral blood flow, EcoColorCodedSonography, ECCS, vertebral flow, vascular vertigo, retinal fluorangiography

\section{RIASSUNTO}

La vascolarizzazione dell'orecchio interno è termino-terminale, questo espone il labirinto a danni da ipossia o ipossia-rivascolarizzazione. Riduzioni ulteriori di flusso ematico potrebbero essere alla base non solo della insorgenza, ma anche della maggiore frequenza di recidive della vertigine parossistica. Allo scopo di valutare l'incidenza di questi fattori abbiamo studiato 50 pazienti, 32 con VPPB ricorrenti e 18 soggetti sani. Tutti $i$ soggetti sono stati sottoposti a esame otoneurologico completo, a valutazione emodinamica con ecocolordoppler (ECD) delle arterie vertebrali con indicazione del flusso in $\mathrm{ml} / \mathrm{min}$ e a fluorangiografia retinica (FAG). Nel gruppo di studio 19 pazienti (59,3\%) all'ECD hanno presentato una riduzione del flusso vertebrale rispetto ai valori di normalità $(<100 \mathrm{ml}$ min). In tutti i casi il lato con maggiore ipoafflusso era lo stesso affetto da VPPB. I restanti 13 pazienti $(40,6 \%)$ avevano valori ECD nella norma. La FAG non ha evidenziato alterazioni vascolari del microcircolo. L'esame ultrasonografico ha dimostrato quindi che il $59 \%$ dei soggetti con VPPB ricorrenti ha una riduzione significativa nel flusso vertebrale omolaterale al lato affetto e che questo valore aumenta al 68,75\% se la differenza del flusso tra le due arterie vertebrali è maggiore del valore soglia riscontrato nei soggetti normali e al $71,8 \%$, se viene considerata anche la presenza di fattori di rischio. In conclusione, lo
Received: October 11, 2019

Accepted: April 13, 2020

Correspondence

Giampiero Neri

Department of Neurosciences Imaging and Clinical Sciences, University Gabriele D'Annunzio of

Chieti-Pescara, Italy, 136-65125

Fax +390871358550

E-mail: giampiero.neri@unich.it

Funding

None.

Conflict of interest

The Authors declare no conflict of interest.

How to cite this article: Neri G, Filograna Pignatelli GR, Pacella A, et al. Recurring paroxysmal positional vertigo: evaluation of the vascular factor. Acta Otorhinolaryngol Ital 2021;41:77-83. https://doi.org/10.14639/0392-100X-N0502

(C) Società Italiana di Otorinolaringoiatria e Chirurgia Cervico-Facciale

\section{(c) (1) $(-)$}

This is an open access article distributed in accordance with the CC-BY-NC-ND (Creative Commons Attribution-NonCommercial-NoDerivatives 4.0 International) license. The article can be used by giving appropriate credit and mentioning the license, but only for non-commercial purposes and only in the original version. For further information: https:// creativecommons.org/licenses/by-nc-nd/4.0/deed.en 
studio evidenzia che il labirinto è molto più sensibile della retina all'insulto ischemico. Infatti, anche in assenza di segni retinici di alterazione del microcircolo, una ridotta perfusione labirintica, precipitando la già precaria irrorazione del labirinto, può determinare la degenerazione della macula utricolare portando al distacco otoconiale e al conseguente sviluppo della VPPB ricorrente. Questa situazione di rischio per il labirinto inoltre può essere svelata dalla valutazione di tre parametri: la presenza di fattori di rischio vascolare, la riduzione del flusso vertebrale $<100 \mathrm{ml} / \mathrm{min}$. e la differenza di flusso tra le 2 arterie vertebrali $>29 \mathrm{ml} / \mathrm{min}$.

KEY WORDS: VPPB, flusso ematico cerebrale, ecocolordoppler, flusso vertebrale, vertigine vascolare

\section{Introduction}

Benign paroxysmal positional vertigo (BPPV) is the most frequent cause of vertigo ${ }^{1}$. The number of relapses is variable, but it has been observed that $27 \%$ of patients suffer from at least one new episode and of these $14 \%$ have one episode, $10 \%$ two relapses and about $3 \%$ of patients have 3 episodes per year ${ }^{2}$. In $50 \%$ of cases, relapses occur within the first 6 months from the onset of the disease. The strong social impact of BPPV has encouraged continuous clinical research that has revealed many aspects of this pathological condition. However, the reasons for the frequent recurrence of idiopathic BPPV, without apparent cause, are yet to be clarified ${ }^{3}$.

A new vertigo episode after a pause almost two months must be interpreted as a new event, where an unknown "facilitating factor" has a relevant role ${ }^{4}$.

At present, there are no diagnostic exams that allow us to observe this "facilitating factor", but when the recurrence is verified, we are normally oriented towards a hypothetical vascular cause ${ }^{5}$.

According to Baloh ${ }^{6}$, vertigo is often caused by vertebrobasilar insufficiency, and is present in many diseases caused by vascular damage, such as cerebellar infarct, lateral medullary infarct, and labyrinth and pons-medullar tract infarct. In two cases, hearing loss was associated with vertigo and caused by either vessel occlusion or simple reduction of vascular flux ${ }^{7,8}$.

The vascularisation of the inner ear depends on the internal auditory artery, a branch of the basilar artery or anterior inferior cerebellar artery, which is a terminal vessel and make the labyrinth sensitive to ischaemic phenomena ${ }^{9}$.

The experimental study on blood flow distribution in the Circle of Willis ${ }^{10,11}$ showed that reductions in cerebral capillary arterial flow in the posterior circulation are directly proportional to reductions in the vertebral arteries flow. Extracranial colour-coded duplex sonography of vertebral arteries (ECCSVA) can be a useful and low-cost screening tool for the evaluation of posterior cerebral circulation ${ }^{12}$. It has been demonstrated, furthermore, that the blood that comes from the two vertebral arteries, after having engaged in the basilar artery, flows separately and is divided from a central zone where the flux is absent, defined "dead point" ${ }^{13}$. This indicates that the perfusion of the labyrinth is not only proportional to the vertebral blood flow, but can also depend on the side in which the flow is reduced.

It is well known that common variations of size and flow capacity between the two vertebral arteries exist, which may range from a slight asymmetry to marked hypoplasia of one side, with prevalence of unilateral vertebral artery hypoplasia between 2 to $25 \%{ }^{14}$. This has also been observed in patients with vertebrobasilar insufficiency ${ }^{15}$ and Seidel ${ }^{16}$ and Jeng ${ }^{17}$ reported that the vertebral artery flow is considered pathological when it is lower than $100 \mathrm{ml} / \mathrm{min}$. The aim of our study is to evaluate the incidence of the vascular factor in recurring BPPV with quantitative analysis of vertebral flow using ECCSVA and the analysis of cerebral microcirculation using retinal fluorangiography (FAG) ${ }^{18}$.

\section{Materials and methods}

Fifty consecutive samples were recruited from January 2016 to December 2017 in our Audiovestibology Unit of the ENT Department in the University Hospital SS Annunziata in Chieti. Of these, 32 patients were affected by recurring idiopathic BPPV with a frequency of recurrence not less than 3 episodes/year, and the remaining 18 subjects were enlisted as the control group.

The exclusion criteria were a recurrence frequency of $<3$ episodes/year; labyrinthine disease different from BPPV, age 70 years and over; a history of trauma or cervico-facial district contusion; and degenerative neurological pathologies.

All patients were informed about the study in detail, which adhered to the Declaration of Helsinki and ICH-GCP, GU $184 / 2003$. Written informed consent was obtained from all patients.

All subjects underwent physical ENT examination, pure tone audiometry, vestibular spontaneous and positional testing using videonystagmoscopy and bithermal caloric evaluation according to Fitzgerald-Hallpike.

The haemodynamic quantitative analysis of vertebral artery flow, expressed in $\mathrm{ml} / \mathrm{min}$, was obtained by the same operator using ECCS Mindray DC-70 through the acoustic windows from the transverse processes of the vertebrae in one segment (or more) of the V2 section. The Doppler waveforms and flux were obtained with an angle of insonation of $60^{\circ}$ or less. On the basis of the literature ${ }^{17}$, we considered 
that a vertebral artery flow of $<100 \mathrm{ml} /$ min was valid indicator of vertebral artery hypoperfusion.

Evaluation of cerebral microcirculation was investigated using retinal fluorescein angiography (FAG).

Finally, we evaluated in each person of both groups the flow difference between the vertebral arteries (D) considering as normal the highest difference found in the control group ( $29 \mathrm{ml} / \mathrm{min}$ ) (Tab. I). Statistical analysis was performed using independent-samples t-test for $\mathrm{P} \leq 0.05$ to determine if a difference exists between two means of two independent groups on continuous dependent variables.

\section{Results}

Fifty subjects, 36 females (72\%) and 14 males (28\%), were included in this study; 32 patients (study group) had recurring BPPV and 18 subjects (control group) had no vertigo or vascular pathologies. Audiometry results showed agerelated disorders in all 50 subjects.

The study population was composed of 22 females (69\%) and 10 males $(31 \%)$ with age ranged between 24 and 70 years (average age 52 years). In this sample, 12 patients

Table I. Vertebral flow in $\mathrm{ml} / \mathrm{min}$ in the control group. We hypothesised that the highest difference in flow between the two arteries $(\Delta=29 \mathrm{ml} / \mathrm{min})$ was the normal limit.

\begin{tabular}{|c|c|c|c|c|}
\hline Patient & Age & $\begin{array}{l}\text { Right Vert. A. } \\
\text { (ml/min) }\end{array}$ & $\begin{array}{l}\text { Left Vert. A. } \\
\text { (ml/min) }\end{array}$ & $\Delta$ \\
\hline C.G. & 56 & 143 & 132 & 11 \\
\hline C.V. & 24 & 108 & 125 & -17 \\
\hline D.A. & 47 & 165 & 176 & -11 \\
\hline D.R.M. & 34 & 104 & 115 & -11 \\
\hline D.F.T & 43 & 115 & 110 & 5 \\
\hline P.T. & 62 & 160 & 188 & -28 \\
\hline D.R. & 49 & 172 & 170 & 2 \\
\hline G.A. & 63 & 151 & 129 & 22 \\
\hline G.L. & 26 & 104 & 109 & -5 \\
\hline L.E. & 65 & 168 & 157 & 11 \\
\hline G.S. & 68 & 166 & 160 & 6 \\
\hline P.R. & 45 & 149 & 165 & -16 \\
\hline R.M. & 50 & 115 & 131 & -16 \\
\hline S.F. & 61 & 157 & 186 & -29 \\
\hline S.L. & 46 & 170 & 154 & 16 \\
\hline M.O. & 67 & 165 & 158 & 7 \\
\hline T.A. & 60 & 163 & 145 & 18 \\
\hline V.M. & 52 & 218 & 195 & 23 \\
\hline & Mean & Mean & Mean & $D$ \\
\hline & 51 & 149.6 & 150.3 & 23 \\
\hline \multicolumn{5}{|c|}{ Standard Deviation } \\
\hline \multicolumn{5}{|c|}{28.2} \\
\hline
\end{tabular}

(37.5\%) presented a documented pathological vascular risk (Tab. I) while in 20 cases (62.5\%), BPPV was idiopathic. The most common vascular risk factors were hypertension (28\%), diabetes (18.7\%) and hyperlipidaemia (15.6\%). Types of BPPV were found to be distributed as right posterior in $11(34 \%)$, right lateral in $6(18.7 \%)$, left posterior in $10(31 \%)$ and left lateral canal in $5(15 \%)$.

In the study group, on bithermal caloric testing 14 patients $(43 \%)$ were found to have labyrinthine hypofunction of the affected side.

Ultrasonography in the control group showed normal vertebral flow in all subjects with values between 104 and $218 \mathrm{ml} / \mathrm{min}$ (average 149.6) in the right side, 109 and $195 \mathrm{ml} / \mathrm{min}$ (150.3) in the left side end with a $\mathrm{D}$ between 2 and $29 \mathrm{ml} / \mathrm{min}$. The ECCSVA in the study group presented in 19 patients $(59.3 \%)$ a reduction in arterial vertebral flow, exceeding the normal range $(<100 \mathrm{ml} /$ $\min$ ) between 26 and $96 \mathrm{ml} / \mathrm{min}, 13$ patients $(40.6 \%)$ demonstrated hypoperfusion on only one side, and 6 patients $(18.75 \%)$ presented a reduction on both sides. In all pathological cases (64\%), BPPV was present on the side where the blood flow was most decreased. The remaining 13 patients $(40.6 \%)$ had a normal VA flow (> $100 \mathrm{ml} /$ min) (Tabs. II, III).

In the 12 patients $(37.5 \%)$ with vascular risk, we detected hypoperfusion in 9 subjects (75\%): unilateral in 4 subjects and bilateral in 5 .

The hypoperfusion in the 20 patients $(62.5 \%)$ with idiopathic BPPV was unilateral in $8(25 \%)$ and bilateral in 2 subjects.

In the study group, the D between the two VAs observed in each patient was superior to the normality range in 21 cases (65.6\%): 9 patients (28.1\%) with vascular risk and 12 patients $(37.5 \%)$ with idiopathic BPPV.

FAG exam in all patients excluded qualitative and dynamic alterations of the retinal situation that could explain the eventual damage at the microcirculatory level.

The results of the control group are shown in Table I.

\section{Discussion}

BPPV is a recurring pathological condition. While a clear clinical diagnosis is available in $86 \%$ of cases ${ }^{19}$, the frequency of relapses depends on unknown causes. Since instrumental exams and imaging are often not capable of demonstrating evident alterations, it is possible that the frequency of relapses may have a facilitating factor that remains unknown.

When it is not possible to identify a definite cause of BPPV, a vascular cause is suspected. The main cause of vascular aetiology is vertebrobasilar ischaemia, generated by pa- 
Table II. Vertebral flow in $\mathrm{ml} / \mathrm{min}$ in BPPV group with vascular risk.

\begin{tabular}{lcccccc} 
Patient & Age & Risk factors & $\begin{array}{c}\text { Right VA } \\
(\mathbf{m l} / \mathbf{m i n})\end{array}$ & $\begin{array}{c}\text { Left VA } \\
(\mathbf{m l} / \mathbf{m i n})\end{array}$ & BPPV & $\Delta$ \\
F.P. & 50 & Hypertension & 140 & 164 & R PSC & 24 \\
D.P.M. & 68 & Diabetes & 81 & 45 & L LSC & 36 \\
D.L.G. & 64 & Hypertension dyslipidaemia & 63 & 198 & R PSC & 135 \\
C.F. & 65 & Hypertension dyslipideamia & 86 & 24 & L PSC & 62 \\
C.S. & 57 & Hypertension diabetes & 49 & 137 & R LSC & 88 \\
S.Z. & 50 & Hypertension diabetes & 96 & 25 & L PSC & 70 \\
L.D.C. & 63 & Hypertension dyslipidaemia & 59 & 182 & R PSC & 123 \\
M.V. & 58 & Hypertension dyslipidaemia & 76 & 44 & L LSC & 32 \\
F.C. & 68 & Diabetes & 52 & 140 & R LSC & 88 \\
G.S. & 66 & Hypertension diabetes & 145 & 155 & R PSC & 10 \\
PP & 62 & Diabetes & 77 & 56 & L PSC & 21 \\
M.C. & 51 & Hypertension dyslipidaemia & 130 & 160 & L PSC & 30 \\
\hline R.SC. Rigt PoS
\end{tabular}

RPSC: Right Posterior Semicircular Canal; R LSC: Right Lateral Semicircular Canal; L LSC: Left Lateral Semicircular Canal; L PSC: Left Posterior Semicircular Canal

Table III. Vertebral flow in $\mathrm{ml} / \mathrm{min}$ in BPPV group without vascular risk.

\begin{tabular}{|c|c|c|c|c|c|}
\hline Patient & Age & $\begin{array}{l}\text { Right VA } \\
\text { (ml/min) }\end{array}$ & $\begin{array}{l}\text { Left VA } \\
\text { (ml/min) }\end{array}$ & BPPV & $\Delta$ \\
\hline C.F. & 56 & 64 & 119 & R PSC & -55 \\
\hline D.L. & 45 & 160 & 189 & R PSC & -29 \\
\hline D.A. & 45 & 89 & 154 & R LSC & -65 \\
\hline D.AR. & 51 & 195 & 129 & LPSC & 66 \\
\hline M.F. & 70 & 128 & 66 & LPSC & 62 \\
\hline T.M. & 64 & 164 & 179 & LPSC & -15 \\
\hline T.R. & 52 & 128 & 129 & R LSC & -1 \\
\hline T.A. & 70 & 66 & 33 & L LSC & 33 \\
\hline L.M. & 58 & 140 & 149 & L LSC & -9 \\
\hline V.L. & 53 & 188 & 160 & R PSC & 28 \\
\hline C.R. & 57 & 72 & 128 & RPSC & -56 \\
\hline F.G. & 58 & 34 & 135 & R PSC & -101 \\
\hline DA.P. & 49 & 170 & 113 & LPSC & 57 \\
\hline M.M & 51 & 198 & 228 & R PSC & -30 \\
\hline D.P.E. & 35 & 133 & 143 & R PSC & -10 \\
\hline C.S. & 57 & 49 & 136 & R LSC & -87 \\
\hline D'A.P. & 36 & 93 & 82 & LPSC & 11 \\
\hline C.P & 56 & 141 & 148 & L LSC & -7 \\
\hline M.M. & 47 & 75 & 110 & LPSC & -35 \\
\hline C.C. & 55 & 87 & 140 & R LSC & -53 \\
\hline
\end{tabular}

R PSC: Right Posterior Semicircular Canal; $R$ LSC: Right Lateral Semicircular Canal; L LSC: Left Lateral Semicircular Canal; L PSC: Left Posterior Semicircular Canal

thologies such as atherosclerosis, congenital or acquired arterial malformation, cervical arthrosis and peripheral microangiopathy ${ }^{4,20}$.

It has been hypothesised that otolith detachment in idiopathic BPPV could be secondary to microvascular problems ${ }^{20,21}$, without necessarily being accompanied by the most important vascular pathologies (myocardial infarction, heart failure, ictus). The reduction in vertebral arterial flow, moreover, might not be significant for organs like the brain or cerebellum, which are endowed with a remarkable compensatory capacity ${ }^{22}$, but can have a significant role in compromising the perfusion of organs supplied by a terminal-type circulation ${ }^{23}$. For example, it might affect the utricular macula or semicircular canals, and this ischaemia of their neuroepithelium can facilitate its degeneration with consequent detachment of otoliths ${ }^{24}$.

In this study, we tried to understand whether the use of tests that specifically explore the vascular district, namely retinal FAG for microcirculation and ECCS for the vertebral artery, may be useful for diagnosis in patients with recurring BPPV. A normal vertebral flow upper to $100 \mathrm{ml} / \mathrm{min}$ was considered. This is in agreement with Jang ${ }^{17}$ who reported a normal limit of vertebral hypoperfusion $<100 \mathrm{ml} / \mathrm{min}$.

The results showed that the retinal FAG is inadequate for indirect evaluation of vestibular microcirculation because patients, even those with verified reduction in vertebral arterial flow, did not present alterations in retinal microcirculation. This result is possibly due to differences between the diameters of the central retinal artery $(0.16 \mathrm{~mm})^{25}$ and internal auditory artery $(0.05 \mathrm{~mm}){ }^{26}$ which makes the labyrinth more susceptible to ischaemia than the eye.

Using ECCS, we found that $59.3 \%$ of subjects in the study group presented a significant reduction in VA flow $(<100 \mathrm{ml} / \mathrm{min}$ ) compared to the control group. Our data is in agreement with the study by Seidel et al. ${ }^{16,17}$. In these subjects, the pathology of the semicircular canal was found to be ipsilateral to the vertebral artery with haemodynamic insufficiency. In 6 cases, where both vertebral arteries had a reduced flow with compared to the mean, the pathology of 
the semicircular canal was ipsilateral to the side most hypo perfused (Tabs. II, III).

The predominance of the VA compared to the one on the contralateral side is physiologically normal. Hence, our study, using statistical analysis on the control group, highlighted that such a prevalence does not exceed the limits of normality (Tab. III).

Our study demonstrated that the reduction of the VA flow, unilateral to the injured side, was present in $59.3 \%$ of patients with recurring BPPV. In particular, it was observed in 10 patients with idiopathic recurring BPPV (31.2\%) and 9 patients (28.1\%) with recurring BPPV and documented vascular risk.

These results confirm the absolute dependence of the vestibular system of one side to the ipsilateral VA flow, as demonstrated by studies of circulatory physiology of the Circle of Willis by Mc Donald and Potter (1951) and Carney (1981) ${ }^{13}$. These studies demonstrated that, inside the basilar artery (BA), the blood flow merger by the two vertebral arteries remains distinct and separated by a zone defined as the "dead point," where the value of vertebral flow is zero. Consequently, the pressure of the flow in the vertebral vessels, measured by ECCS in $\mathrm{ml} / \mathrm{min}$ (Fig. 1), was found to be directly proportional to the flow of the ipsilateral internal auditory artery.

Another parameter considered is D which represents the highest difference in flow values registered between the two vertebral arteries (Tabs. II, III). In the healthy subjects of our case series (Tab. I), this value is $29 \mathrm{ml} / \mathrm{min}$. In the study group, this parameter was greater than $29 \mathrm{ml} /$ min in 21 patients $(65.6 \%)$, and most precisely 12 of them $(37.5 \%)$ among those without vascular risk and $9(28.1 \%)$ with reported vascular risk.

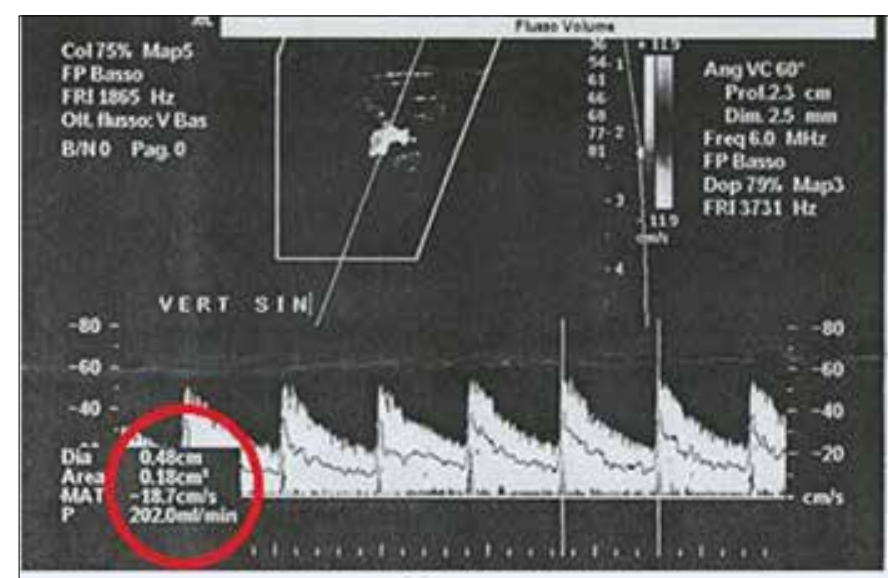

a
Notably, the results of the two parameters (D and flow in $\mathrm{ml} /$ min) are comparable and documented independently from each other, along with the validity of the methodology and their extreme correlation with the onset of recurring BPPV. The study of blood flow distribution on experimental models of the Circle of Willis, constructed by David in $2002^{10}$ showed that blood confluence from the vertebral arteries into the basilar artery is almost diverted into the larger artery like the posterior cerebral artery. It was also demonstrated that only a moderate quantity of blood is distributed in smaller vessels, like the posterior cerebellar artery, and above all, the internal auditory artery. In other words, the labyrinth is physiologically less supplied.

In this situation, further reduction in perfusion can precipitate an already critical condition that can translate into labyrinthine suffering.

However, ischaemia cannot be compensated by the flow of the opposite vertebral artery because, as previously mentioned, the flow of the two vertebral arteries remains separated inside the basilar artery. This can be translated into degeneration of the utricular macula with repeated detachment of otolith material and consequent BPPV ${ }^{27}$. Therefore, we can legitimately hypothesise that the influence of general factors, like the vascular factors during persistent ischaemic states in the vertebrobasilar area lead to secondary distress of neuroepithelial structures of the macula, which can be followed by detachments of the otoconial membrane ${ }^{28}$. This could also be the cause of the subclinical labyrinthine hypofunction revealed by the bithermal caloric tests in $40 \%$ of our sample.

Deterioration of the circulation in the vertebral artery, which is already hypofunctional, can result in the alteration of the endothelial wall, which might even be insignificant and not

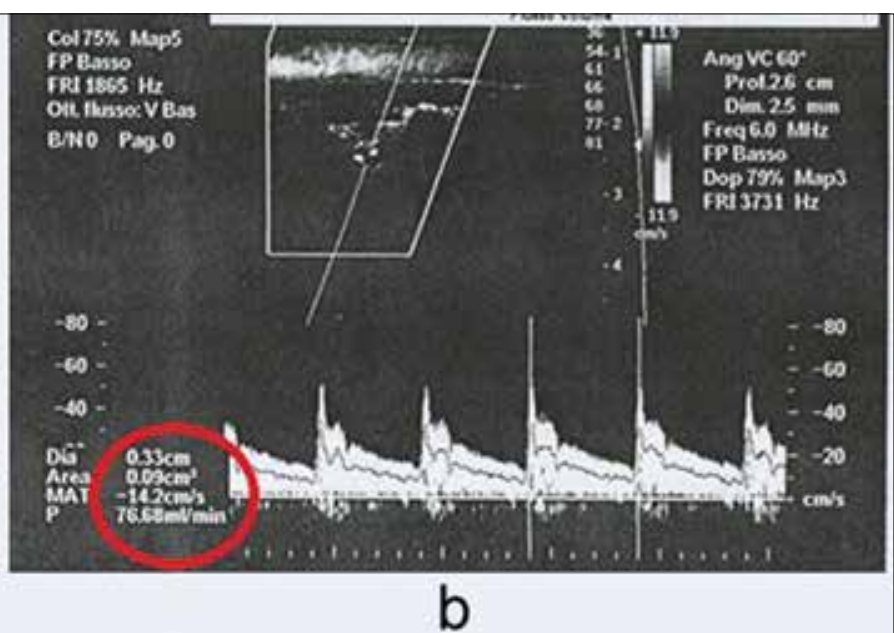

Figure 1. ECCS of the vascular vertebral left (A) and right (B) arteries fFlow value in $\mathrm{ml} / \mathrm{min}$ is circled in red). 
appreciable with any diagnostic technique. As demonstrated by Fischer in 2002, in carotid circulation the presence of stenosis, atherosclerosis, or flow obstruction can generate turbulence capable of further stenosis and worsened altered circulation ${ }^{23}$. This could also explain why BPPV is related to future ischaemic strokes regardless of age ${ }^{29}$.

\section{Conclusions}

A correct interpretation of vascular vertigo is of extreme prognostic importance because isolated and repeated episodes of vertigo can precede stroke in a relevant number of cases. In $25 \%$ of patients with basilar artery obstruction, recurring vertigo was revealed to be the symptom in $50 \%$ of patients during autopsy, while in $60-70 \%$ of subjects who subsequently developed a vascular deficit, vertigo is the principal symptom. A brief episode of vertigo frequently occurs during the three days immediately preceding the stroke, or during the last six weeks. These observations suggest that when diagnosing BPPV it is very useful to utilise other diagnostic, and not vestibological, tools, such as ECCS of the VA, which gives information directly on labyrinthic vascular flow. It is possible to consider the results of this exam as a new risk factor for recurrent BPPV and vascular risk.

In conclusion, from our results, we confirm that ultrasound examination of the vertebral arteries represents a method of choice in the diagnosis of recurring vascular vertigo, provided that the vertebral artery flow is specifically measured in $\mathrm{ml} / \mathrm{min}$ and not in $\mathrm{cm} / \mathrm{sec}$ as normally occurs in ultrasound laboratories. This value, in fact, does not indicate the flow rate of blood, but rather the speed relative to the caliber of the artery, an observation therefore only indirect and in our opinion not very significant. The absence of fluorangiographic signs suggests that the labyrinthine neuroepithelium is much more sensitive to hypoperfusion than the retina. For this reason, the labyrinth could be considered to be a more reliable sentinel than the retina to intercept microcirculatory vascular disorders even earlier. BPPV, especially if recurrent, should always be evaluated with ECCS to reveal possible signs of hypoperfusion. The vascular risk situation for the labyrinth can also be better revealed by evaluation of all three parameters: presence of vascular risk factors, reduction of vertebral flow $<100 \mathrm{ml} / \mathrm{min}$ and the difference in flow between the 2 vertebral arteries $>29 \mathrm{ml} /$ $\mathrm{min}$. Moreover, this data is confirmed empirically by the reduction in recurring vertigo subsequent to the use of drugs that activate the microcirculation like betahistine ${ }^{27}$, mesoglycan, or sulodexide ${ }^{30}$.

\section{References}

1 von Brevern M, Radtke A, Lezius F, et al. Epidemiology of benign paroxysmal positional vertigo: a population based study. J Neurol Neurosurg Psychiatry 2007;78:710-5. https://doi.org/10.1136/jnnp.2006.100420

2 Pérez P, Franco V, Cuesta P, et al. Recurrence of benign paroxysmal positional vertigo. Otol Neurotol 2012;33:437-43. https:// doi:10.1097/MAO.0b013e3182487f78

3 Casani A, La Vertigine Ricorrente: una sfida per l'otoneurologo. Acta Otorhinolaryngol Ital 2003;75:6-18.

4 Nuti D, Gaudini E, Salerni L. Vertigini ricorrenti a eziologia vascolare. Acta Otorhinolaryngol Ital 2003;75:33-8

5 Kashimada A, Machida K, Honda N, et al. Measurement of cerebral blood flow with two-dimensional cine phase-contrast MR imaging: evaluation of normal subjects and patient with vertigo. Radiat Med 1995;13:95-102.

6 Baloh RW,Vertebrobasilar insufficiency and stroke. Otolaryngol Head Neck Surg 1995;112:114-7. https://doi.org/10.1016/s0194-5998(95)70309-8

7 Doyle KJ, Fowler C, Starr A. Audiologic findings in unilateral deafness resulting from contralateral pontine infarct. Otolaryngol Head Neck Surg 1996;114:482-6. https://doi.org/10.1016/s01945998(96)70224-3

8 Yamasoba T, Kikuchi S, O’Uchi T, et al. Magnetic resonance angiographic patients with slow vertebrobasilar blood flow. Acta Otolaryngol 1995(Suppl);115:153-6. https://doi. org/10.3109/00016489509125215

9 Seo T, Tominaga S, Sagakami M. Relationship between neurological asymptomatic vertigo and vertebrobasilar system as revealed by MR-angiography. ORL J Otorhinolaryngol Relat Spec 2000;62:63-7. https://doi.org/10.1159/000027719

10 David T, Ferrandez A, Brown M. Computational model of blood flow in the Circle of Willis. Comput Methods Biomech Biomed Engin 2000;4:1-26. https://doi.org/10.1080/10255840008907996

11 Šutalo ID, Bui AV, Ahmed S, et al. Modeling of flow through the Circle of Willis and cerebral vasculature to assess the effects of changes in the peripheral small cerebral vasculature on the inflows. Engineering Applications of Computational Fluid Mechanics 2014;8:4, 60922. https://doi.org/10.1080/19942060.2014.11083311

12 Nazerian P, Bigiarini S, Pecci R, et al. Duplex sonography of vertebral arteries for evaluation of patients with acute vertigo. Ultrasound Med Biol 2017;44:584-92. https://doi.org/10.1016/j.ultrasmedbio.2017.11.002

13 Carney AL. Vertebral artery surgery: historical development, basic concepts of brain hemodynamic, and clinical experience of 102 cases. Adv Neurol 1981;30:249-82.

14 Park JH, Kim JM, Roh JK. Hypoplastic vertebral artery: frequency and associations with ischemic stroke territory. J Neurol Neurosurg Psychiatry 2007;78:954-8. https://doi.org/10.1136/jnnp.2006.105767

15 Miura M, Naito Y, Naito E, et al. Usefulness of magnetic resonance imaging in diagnosing vertebrobasilar insufficiency. Acta Otolaryngol Suppl 1997;528:91-3.

16 Seidel E, Eicke BM, Tettenborn B, et al. Reference values for vertebral artery flow volume by duplex sonography in young and elderly adults. Stroke 1999;30:2692-6. https://doi.org/10.1161/01.str.30.12.2692

17 Jeng JS, Yip PK. Evaluation of vertebral artery hypoplasia and asymmetry by color-coded duplex ultrasonography. Ultrasound Med Biol 2004;30:605-9. https://doi.org/10.1016/j.ultrasmedbio.2004.03.004

18 Menchini U, D'Ettorre M, Mondelli M, et al, The use of retinal fluorangiography tecniques in the study of cerebral circulation. Cephalgia 1985;2:59-63. https://doi.org/10.1177/03331024850050s210

19 Nuti D, Caruso G, Salerni L, et al. Epidemiologia e caratteristiche cliniche della vertigine parossistica posizionale benigna: 10 anni di esperienza. Arq Otorrinolaringol 2003;7. 
20 Barbieri M, Mora R, Barbieri A. Eziologia della vertigine parossistica posizionale. In: Nuti D, Pagnini P, Vicini C, editors. Revisione critica di venti anni di vertigine parossistica posizionale benigna (VPPB). Milano: Comitato Simposi Scientifici Formenti 1999, pp. 55-8.

21 Guidetti G. Diagnosi e terapia dei disturbi dell'equilibrio. Roma: Marrapese Editore 1997.

22 Gutmann R, Wollemberg B, Krampert B, et al. Incidence of Doppler ultrasound detectable stenoses of cervical arteries in patients with cochlear-vestibular symptoms. Laryngorhinootologie 1993;72:502-5. https://doi.org/10.1055/s-2007-997945

23 Katsanos AH, Kosmidou A, Kyritsis AP, et al. Is vertebral artery hypoplasia a predisposing factor for posterior circulation cerebral ischemic events? A comprehensive review. Eur Neurol 2013;70:78-83. https://doi.org/10.1159/000351786

24 Casani AP, Dallan I, Marchetti M, Ruolo dei potenziali evocati vestibolari miogenici nella diagnostica vestibolare. Acta Otorhinolaryngol Ital 2003;23(Suppl 75)5:113-9.

25 Dorner GT, Polska E, Garhöfer G, et al. L Calculation of the diameter of the central retinal artery from noninvasive measurements in humans. Curr Eye Res 2002;25:341-5. https://doi:10.1076/ ceyr.25.6.341.14231

26 Haidara A, Peltier J, Zunon-Kipre Y, et al. Microsurgical anatomy of the labyrinthine artery and clinical relevance. Turk Neurosurg 2015;25:539-43. https://doi:10.5137/1019-5149.JTN.9136-13

27 Toupet M. Betahistine and vestibular function. Unexpected therapeutical implications. In: Aggiornamenti di vestibologia $2^{\circ}$ ed. Atti congressuali. Milano: Energy editions, Energy S.r.l. 2005, pp. 77-82.

28 Faralli M, Ricci G, Frenguelli A, et al. Paroxysmal positional vertigo: the role of possible vascular factors in etiology. Mediterr J Otol 2006;2:63-9.

29 Kao CL, ChengYY, Leu HB, et al. Increased risk of ischemic stroke in patients with benign paroxysmal positional vertigo: a 9-year followup Nationwide Population Study in Taiwan. Front Aging Neurosci 2014;108:1-7. https://doi.org/10.3389/fnagi.2014.00108

30 Neri G, Marcelli V, Califano L, et al. Assessment of the effect of mesoglycan in the treatment of audiovestibular disorders of vascular origin. Int J Immunopathol Pharmacol 2018;32:2058738418773833. https://doi:10.1177/2058738418773833 